\title{
Effects of task-oriented training for Gross Motor Function Measure, balance and gait function in persons with cerebral palsy
}

\author{
Hyun-Kyung Han ${ }^{a}$, Yijung Chung ${ }^{b}$ \\ ${ }^{a}$ Department of Physical Therapy, The Graduate School, Sahmyook University, Seoul, Republic of Korea \\ ${ }^{b}$ Department of Physical Therapy, College of Health and Welfare, Sahmyook University, Seoul, Republic of Korea
}

\begin{abstract}
Objective: This study was to investigate the effects of Task-oriented training for Gross Motor Function Measure (GMFM), gait and balance function in cerebral palsy.
\end{abstract}

Design: Randomized controlled trials.

Methods: Twenty four subjects were recruited by means of a convenience sampling from Kangseo-Gu $\mathrm{G}$ rehabilitation center. Subjects were 24 inpatients and were randomly divided into a task-oriented training group and a conventional group. Twelve patients were experimental group who executed the task-oriented training ( 5 times/wk) for 4 weeks. The task-oriented program mainly focused on the capabilities of independent walking, with the angle of inclination set at 0 degrees and walking at a self-selected comfortable speed. In addition, balance training included the one-legged standing with weight-shifting and task-oriented training. Twelve patients were control group who executed only general conventional therapy ( 5 times/wk) for 4 weeks. All subjects were evaluated about the motor function, gait and balance function. Subjects have conducted the measured variables, GMFM, GAITRite, PDM Multifunction Force Measuring Plate after treatment.

Results: There was statistically significant increase of Gross Motor Function Measure scores of the experimental group and control group after 4 weeks $(p<.05)$. There was statistically significant increase of gait and balance function of the experimental group after 4 weeks of task-oriented training $(p<.05)$. The experimental group showed a significantly improvement in GMFM, gait, and balance compared to the control group $(p<0.05)$.

Conclusions: This study proved that task-oriented training after stroke can improve Gross Motor Function Measure, gait and balance. Thus this study can suggest that task-oriented training for gross motor function, gait and balance be effective on the cerebral palsy.

Key Words: Cerebral palsy, Gait, Balance

\section{Introduction}

Cerebral palsy (CP) is caused by a lesion generated in the brain that occurs during the early stages of life and is considered as a non-progressing chronic motor disorder, leading to paralysis and muscle spasms of one or more extremities [1]. Children with cerebral palsy commonly experience difficulty with walking and with daily life performance due to muscle tone abnormalities, such as spasticity, muscle weakness [2-4].
The clinical approach of physical therapy for children with cerebral palsy has been influenced by several clinical scientists, which included a variety of neurophysiological treatment methods [5]. The evaluation and treatment methods that have been developed were focused on kinetic problems such as abnormal muscle tone, abnormal reflexes, and abnormal movement patterns, with the tendency to neglect functional movement [6].

However, due to the shift in focus on functional movements rather than solely on muscle activity or movement

Received: 1 March, 2016 Revised: 22 March, 2016 Accepted: 22 March, 2016

Corresponding author: Yijung Chung

Department of Physical Therapy, College of Health and Welfare, Sahmyook University, 815 Hwarang-ro, Nowon-gu, Seoul 01795, Republic of Korea Tel: 82-2-3399-1639 Fax: 82-2-3399-1639 E-mail: yijung36@syu.ac.kr

(c) This is an Open-Access article distributed under the terms of the Creative Commons Attribution Non-Commercial License (http://creativecommons.org/licens es/by-nc/4.0) which permits unrestricted non-commercial use, distribution, and reproduction in any medium, provided the original work is properly cited.

Copyright $@ 2016$ Korean Academy of Physical Therapy Rehabilitation Science 
patterns, there has been a recent assessment method based on the system model of motor control called the task-oriented approach [7,8]. This task-oriented approach regards the children with cerebral palsy as active participants for learning. In addition, the task-oriented approach provides motivation due to specific achievements that can be made [8].

The task-oriented approach effectively provides various sensory stimulation and promotes functional activities as one form of treatment based on the motor learning to a patient. It is comprised of tasks in which it can actually assist in improving daily life operating abilities, which have been suggested to be a more efficient method of treatment $[8,9]$.

Concrete tasks are considered to be more useful than abstract tasks [10]. The usability of task-oriented training is supported through constraint-induced therapy [7]. In many studies, it is reported that a task-oriented program is useful in upgrading and improving the effectiveness of the medical treatment [11].

The task-oriented research involving stroke patients are actively being conducted, more attention is becoming directed onto muscle strengthening in children with cerebral palsy [8]. It has been reported that muscle-strengthening interventions showed not only an increase in muscle strength, but also improved motor function in children with cerebral palsy [12-14]. Blundell et al. [15] focused on task performance and strengthening exercises of specific lower extremity muscles and has reported that it was effective in improving muscular strength in children with cerebral palsy as well as increase range of motion. Also, treadmill training with partial body weight support has been proven to be effective in restoring gait in hemiparetic subjects and children with cerebral palsy $[16,17]$.

Accordingly, the objective of this research was to inquire about the effect of task-oriented training in children with cerebral palsy on the regulation ability of gross motor function, balance, and gait. Moreover, the study has been conducted in order to verify the effectiveness of task-oriented training and develop a more effective therapeutic approach for children with cerebral palsy.

\section{Methods}

\section{Subjects}

This study included thirty children with cerebral palsy who were between the ages of 7-15 years old from the Disabled Person Synthesis Welfare Center in Seoul and was conducted for four weeks. All participants have signed an informed consent after being informed of the purpose of the study. The inclusion criteria of the subjects were as follows: those who were able to understand the instructions provided by the researcher, those without additional neurological or musculoskeletal diseases, those who have not had a posterior rhizotomy or have not been previously medicated with botulum toxin or baclofen within 6 months prior to the study, those who were able to ambulate over $5 \mathrm{~m}$ independently, those without a vision disorder (legally blind), and those who had fully agreed to participate in the study. A consent form of agreement and signature was obtained from the childrens' guardians for participation of the study.

\section{Intervention}

The subjects were divided into a task-oriented training group and a conventional group and were assessed for the gross motor function measure (GMFM), balance and gait as outcome measures prior to the intervention. Aside from conventional therapy, the task-oriented training group received treatment once a day for 30 minutes, 5 times a week, starting with the previous level of intensity and gradually increasing the load when they were able to perform the former intensity amount at an optimal level. The subjects received the training 5 times a week for 4 weeks, totaling up to 20 treatment sessions. The conventional therapy included neurodevelopmental treatment for 40 minutes. The GMFM, balance, and gait parameters were analyzed after 4 weeks. The task-oriented program mainly focused on the capabilities of independent walking, with the angle of inclination set at 0 degrees and walking at a self-selected comfortable speed for 20 minutes (Stex 8000 TL; Sinnara Sports, Suwon, Korea). In addition, balance training included the one-legged standing with weight-shifting and task-oriented training. For safety purposes, subjects were supervised while training on the treadmill. Weight-shifting on one lower extremity while standing and the task-oriented training program was performed on a wooden staircase that was $75 \mathrm{~cm}$ in length, 25 $\mathrm{cm}$ in width, and $10 \mathrm{~cm}$ in height, with the subject's foot placed onto the first step, maintained for 10 seconds, and then lowered back down for a total of 10 minutes.

\section{Outcome measures}

The GMFM is used to assess children with cerebral palsy who are between the ages of $0-18$ years and has a test-retest reliability of intraclass correlation coefficient $=0.94$ and 1.00 for the dimension scores [18]. 
It is composed of a variety of questions with several dimensions; dimension A (Lying \& Rolling) includes 17 questions, dimension B (sitting) includes 20 questions, dimension $\mathrm{C}$ (crawling, kneeling) includes 13 questions, dimension $\mathrm{D}$ (standing) includes 13 questions, and dimension $\mathrm{E}$ (walking/running/jumping) includes 24 questions, totaling up to 88 questions. Gait velocity, cadence, and relevant gait parameters were measured using the GAITRite (CIR Systems Inc., Lafayette, NJ, USA). The GAITRite is reported to have a very high reliability [19]. The GAITRite is a gait analysis system and an electronic gait analyzing board consisting of a 192 inches $(488 \mathrm{~cm})$ electrical walkway that contains six sensor pads encapsulated in a roll-up carpet to produce an active area that is 24 inches $(61 \mathrm{~cm})$ wide and $0.6 \mathrm{~cm}$ high. The active area is a grid with 48 sensors by 384 sensors, with a distance of 0.5 inch $(1.27 \mathrm{~cm})$ between each sensor, totaling up to 16,128 sensors. A sampling rate of $80 \mathrm{~Hz}$ was used to measure the loading of the subject's feet when the subjects walk on it. A serial interface cable was used to transmit data. Spatiotemporal data collected was processed using the GAITRite GOLD, version 3.2b software. Subjects were instructed to stand in front of the gait board, and then walk at a self-selected speed.

Balance was assessed using the pressure measurement devices Multifunction Force Measuring Plate (2004; Zebis Medical GmbH, Isny im Allgäu, Germany) with the subject's eyes open and closed while the velocity and sway of the center of pressure (COP) were measured. The system includes a pressure that consists of 2,560 embedded sensors, and the pressure is recorded by each sensor.

Analysis

Statistical analysis was performed using Windows SPSS ver. 12.0 for windows (SPSS Inc., Chicago, IL, USA). Com-

Table 1. Characteristics of participants

$(\mathrm{N}=24)$

\begin{tabular}{lccc}
\hline \multicolumn{1}{c}{ Variable } & $\begin{array}{c}\text { Experimental } \\
\text { group }(\mathrm{n}=12)\end{array}$ & $\begin{array}{c}\text { Control group } \\
(\mathrm{n}=12)\end{array}$ & $\chi^{2} / \mathrm{t}$ \\
\hline Male & 7 & 8 & 1.397 \\
Female & 5 & 4 & \\
Hemiplegia type & 2 & 3 & \\
Paraplegia type & 7 & 5 & 0.676 \\
Quadriplegia type & 3 & 4 & \\
Age $(\mathrm{y})$ & $10.30(0.18)$ & $10.56(2.46)$ & 0.431 \\
Height $(\mathrm{cm})$ & $130.00(8.37)$ & $132.21(2.91)$ & 0.741 \\
Weight $(\mathrm{kg})$ & $29.06(2.36)$ & $30.29(6.90)$ & 0.691 \\
\hline
\end{tabular}

Values are presented as number only of mean (SD). parisons between pre and post-treatment within each group were analyzed using the Wilcoxon test. In order to investigate whether if there was a greater change in the experimental group compared with the control group, the change values for each group have been calculated and compared by using the independent t-test. Significance level was set at $p<0.05$.

\section{Results}

General characteristics of the subjects and informed consent

\section{General characteristics of subjects}

The general characteristics of subjects are listed as below (Table 1). Among the children with spastic cerebral palsy, there were 9 female subjects, and 15 male subjects. There were 5 subjects with hemiplegia, 12 with paraplegia, 7 with quadriplegia, with the highest proportion of the subjects with paraplegia. The average age of the subjects in the task-oriented training group was $10.30(0.48)$ years of age, and 10.56 (2.46) years for the control group. The average height of the task-oriented training group was 130.00 (8.37) $\mathrm{cm}$, and $132.51(2.91) \mathrm{cm}$ for the control group. The average weight for the task-oriented training group was $29.06 \mathrm{~kg}$, and 30.29 (6.90) kg for the control group. There were no significant differences among the general characteristics among all subjects (Table 1).

Changes in GMFM scores, balance ability, and gait parameters between the task-oriented training group and control group

Changes in GMFM scores within the task-oriented training group and control group

The GMFM scores of the task-oriented training group was 71.47 (14.00) prior to intervention, and 72.32 (13.78)

Table 2. Changes in Gross Motor Function measure scores

\begin{tabular}{lccc} 
& & & $(\mathrm{N}=24)$ \\
\hline \multicolumn{1}{c}{ Variable } & $\begin{array}{c}\text { Experimental group } \\
(\mathrm{n}=12)\end{array}$ & $\begin{array}{c}\text { Control group } \\
(\mathrm{n}=12)\end{array}$ & $\mathrm{t}$ \\
\hline Pre-test & $71.47(14.00)$ & $71.49(18.66)$ & \\
Post-test & $72.32(13.78)$ & $71.63(18.63)$ & \\
Change value & $0.85(0.55)$ & $0.13(0.15)$ & $4.346^{*}$ \\
$\mathrm{t}$ & $5.339^{* * *}$ & $31.39^{* *}$ & \\
\hline Values are presented as mean (SD). & & \\
${ }^{*} p<0.05, \quad p<0.01, \quad{ }^{* * *} p<0.001$. &
\end{tabular}


Table 3. Changes in ability to balance

$(\mathrm{N}=24)$

\begin{tabular}{clccc}
\hline \multicolumn{1}{c}{ Variable } & $\begin{array}{c}\text { Experimental } \\
\text { group }(\mathrm{n}=12)\end{array}$ & $\begin{array}{c}\text { Control group } \\
(\mathrm{n}=12)\end{array}$ & $\mathrm{t}$ \\
\hline Total & Pre-test & $42.92(2.15)$ & $6.32(3.87)$ & \\
speed & Post-test & $3.23(1.32)$ & $5.84(4.04)$ & \\
$(\mathrm{cm} / \mathrm{s})$ & Change value & $1.69(1.44)$ & $0.46(1.16)$ & $2.257^{*}$ \\
& $\mathrm{t}$ & $4.073^{* *}$ & 1.457 & \\
Total & Pre-test & $59.74(26.26)$ & $76.81(47.03)$ & \\
distance & Post-test & $39.34(16.06)$ & $70.67(49.05)$ & \\
$(\mathrm{cm})$ & Change value & $20.40(17.46)$ & $6.14(14.09)$ & $2.202^{*}$ \\
& $\mathrm{t}$ & $4.048^{* *}$ & 15.10 & \\
\hline
\end{tabular}

Values are presented as mean (SD).

${ }^{*} p<0.05, \stackrel{*}{p} p<0.01$.

post-intervention, with an increase in $0.85(0.55)$. The GMFM scores of the control group was 71.49 (18.66) prior to intervention and 71.63 (18.63) post-intervention, and an increase of $0.13(0.15)$ (Table 2).

\section{Changes in balance ability in the task-oriented training} group and control group

The total speed of the force plate values in the task-oriented training group was $4.92(2.15) \mathrm{cm} / \mathrm{s}$ prior to intervention, and $3.23(1.32) \mathrm{cm} / \mathrm{s}$ after intervention, with a decrease of $1.69(1.44) \mathrm{cm} / \mathrm{s}$. The total distance of the COP was $59.74(26.26) \mathrm{cm}$ prior to intervention, and $39.34(16.06) \mathrm{cm}$ after intervention, with a total decrease of $20.40(17.46) \mathrm{cm}$. The total speed of the force plate values in the control group was $6.32(3.87) \mathrm{cm} / \mathrm{s}$ prior to intervention, and $5.84(4.04)$ $\mathrm{cm} / \mathrm{s}$ after intervention, with a decrease of $0.49(1.16) \mathrm{cm} / \mathrm{s}$. The total distance was $76.81(47.03) \mathrm{cm}$ prior to intervention, and $70.67(49.05) \mathrm{cm}$ post-intervention, with a decrease of $6.14(14.09) \mathrm{cm}$, with no significant differences in the control group (Table 3).

\section{Changes in gait in the task-oriented training group and} control group

According to the gait analysis results, the cadence increased from 29.05 (8.80) steps/min to 54.23 (14.95) steps/min, with a total increase of 25.18 (17.02) steps/min within the task-oriented training group. The gait speed was $0.41(0.14) \mathrm{cm} / \mathrm{s}$ prior to intervention, and $1.27(0.79) \mathrm{cm} / \mathrm{s}$ after intervention, with an increase of $0.86(0.81) \mathrm{cm} / \mathrm{s}$ for the task-oriented training group. The functional gait index score was 53.14 (7.94) prior to intervention, and 68.39 (10.46) post-intervention, with an increase of 15.25 (10.25) for the task-oriented training group. For the control group,
Table 4. Changes in gait parameters

$(\mathrm{N}=24)$

\begin{tabular}{clccc}
\hline \multicolumn{2}{c}{ Variable } & $\begin{array}{c}\text { Experimental } \\
\text { group }(\mathrm{n}=12)\end{array}$ & $\begin{array}{c}\text { Control group } \\
(\mathrm{n}=12)\end{array}$ & $\mathrm{t}$ \\
\hline Cadence & Pre-test & $29.05(8.80)$ & $36.76(21.92)$ & \\
(steps/min) & Post-test & $54.23(14.95)$ & $42.55(17.33)$ & \\
& Change value & $25.18(17.02)$ & $5.79(26.50)$ & $2.133^{*}$ \\
& $\mathrm{t}$ & $-5.124^{* * *}$ & -0.757 & \\
Gait speed & Pre-test & $0.41(0.14)$ & $0.46(0.24)$ & \\
$(\mathrm{cm} / \mathrm{s})$ & Post-test & $1.27(0.79)$ & $0.64(0.35)$ & \\
& Change value & $0.86(0.81)$ & $0.14(0.19)$ & $2.965^{*}$ \\
& $\mathrm{t}$ & $-0.367^{* *}$ & $-2.728^{*}$ & \\
Functional & Pre-test & $53.14(7.94)$ & $55.58(10.88)$ & \\
gait index & Post-test & $68.39(10.46)$ & $60.00(12.14)$ & \\
(score) & Change value & $15.25(10.25)$ & $4.42(5.26)$ & $3.256^{* *}$ \\
& $\mathrm{t}$ & $-5.152^{* * *}$ & $-2.908^{*}$ & \\
\hline
\end{tabular}

Values are presented as mean (SD).

${ }^{*} p<0.05,{ }^{* *} p<0.01,{ }^{* * *} p<0.001$.

the cadence was 36.76 (21.92) steps/min prior to intervention, and 42.55 (17.33) steps/min post-intervention, with an increase of $5.79(26.50) \mathrm{steps} / \mathrm{min}$. The gait velocity was $0.49(0.24) \mathrm{cm} / \mathrm{s} 0.64(0.35) \mathrm{cm} / \mathrm{s}$, with a decrease of 0.14 $(0.19) \mathrm{cm} / \mathrm{s}$. The functional gait index was 55.58 (10.88) prior to intervention and 60.00 (12.14) post-intervention, with a total increase of 4.42 (5.26) (Table 4).

\section{Discussion}

The purpose of this study was to prove the effects of task-oriented training by assessing the GMFM, balance and gait. Moreover, it was performed in order to investigate a treatment approach that can improve the overall function of children with cerebral palsy.

The task-oriented program was comprised of walking on a treadmill beginning at a self-selected comfortable speed by the patient, and then progressed to a more difficult intensity, as well as performing one-legged standing for balance. Although task-oriented training was used to elicit a positive therapeutic effect on the functional prognosis of children with cerebral palsy.

The purpose of this study was to establish the effect of task-oriented training on gait and balance recovery in children with cerebral palsy. The exercises in this study were designed to increase strength to the level required by the task rather than to maximize muscle force production.

The major findings were that a task-oriented program of motor training, carried out as circuit training, resulted in in- 
creased functional ability and improved performance of walking and balance. These gains were maintained for four weeks following cessation of training. The findings are in agreement with other studies, which have shown that strength training in patients with cerebral palsy is associated with improvements in motor function [8]. Performed repetitively in task-oriented training, they would be expected to refine the efficient motor patterns required for optimal functional performance $[20,21]$. The improvements in walking ability seem to favor the concept of using a repetitive taskspecific approach in children with cerebral palsy who are undergoing gait training $[8,22]$.

In this research, a treadmill was used as task-oriented training for gait. Previous studies have shown that the use of a treadmill was effective in improving the isokinetic muscular strength and body composition of children with cerebral palsy [23]. Katz-Leurer et al. [24] reported that motor programs in the form of task-oriented training performed in a home setting is effective in improving motor function and balance abilities in children with cerebral palsy. Drouin et al. [25] has reported a high correlation between the spatiotemporal variables of gait and GMFM scores in children with cerebral palsy. Ross and Engsberg [19] also demonstrated that there was a high correlation between GMFM scores, muscular strength, and gait performance.

Accordingly, task-oriented training along with conventional therapy is regarded as the training method that is effective in improving functional ability, balance, and walking abilities in children with cerebral palsy.

Therefore, results of this study support that a task-oriented program can improve basic functional ability, balance, and walking efficiency in children with cerebral palsy and can provide guidance in training methods. However, in planning a task-oriented program, the ability of a patient, task specificity, frequency, and timing of the tasks should be considered in order to produce an intensive training program.

\section{Conflict of Interest}

The authors declared no potential conflicts of interest with respect to the authorship and/or publication of this article.

\section{References}

1. Krigger KW. Cerebral palsy: an overview. Am Fam Physician 2006;73:91-100
2. Maruishi M, Mano Y, Sasaki T, Shinmyo N, Sato H, Ogawa T. Cerebral palsy in adults: independent effects of muscle strength and muscle tone. Arch Phys Med Rehabil 2001;82:637-41.

3. Eek MN, Beckung E. Walking ability is related to muscle strength in children with cerebral palsy. Gait Posture 2008;28: 366-71.

4. Chang FM, Rhodes JT, Flynn KM, Carollo JJ. The role of gait analysis in treating gait abnormalities in cerebral palsy. Orthop Clin North Am 2010;41:489-506.

5. Maćków A, Małachowska-Sobieska M, Demczuk-Włodarczyk E, Sidorowska M, Szklarska A, Lipowicz A. Influence of neurophysiological hippotherapy on the transference of the centre of gravity among children with cerebral palsy. Ortop Traumatol Rehabil 2014;16:581-93.

6. Damiano DL, Vaughan CL, Abel MF. Muscle response to heavy resistance exercise in children with spastic cerebral palsy. Dev Med Child Neurol 1995;37:731-9.

7. Schneiberg S, McKinley PA, Sveistrup H, Gisel E, Mayo NE, Levin MF. The effectiveness of task-oriented intervention and trunk restraint on upper limb movement quality in children with cerebral palsy. Dev Med Child Neurol 2010;52:e245-53.

8. Salem Y, Godwin EM. Effects of task-oriented training on mobility function in children with cerebral palsy. NeuroRehabilitation 2009;24:307-13.

9. Kim Y, Lee BH. Clinical usefulness of child-centered task-oriented training on balance ability in cerebral palsy. J Phys Ther Sci 2013;25:947-51.

10. Wu C, Trombly CA, Lin K, Tickle-Degnen L. A kinematic study of contextual effects on reaching performance in persons with and without stroke: influences of object availability. Arch Phys Med Rehabil 2000;81:95-101.

11. Kim SH, Park JH, Jung MY, Yoo EY. Effects of task-oriented training as an added treatment to electromyogram-triggered neuromuscular stimulation on upper extremity function in chronic stroke patients. Occup Ther Int 2016. doi: 10.1002/oti.1421. [Epub ahead of print]

12. Damiano DL, Abel MF. Functional outcomes of strength training in spastic cerebral palsy. Arch Phys Med Rehabil 1998;79: 119-25.

13. Dodd KJ, Taylor NF, Damiano DL. A systematic review of the effectiveness of strength-training programs for people with cerebral palsy. Arch Phys Med Rehabil 2002;83:1157-64.

14. MacPhail HE, Kramer JF. Effect of isokinetic strength-training on functional ability and walking efficiency in adolescents with cerebral palsy. Dev Med Child Neurol 1995;37:763-75.

15. Blundell SW, Shepherd RB, Dean CM, Adams RD, Cahill BM. Functional strength training in cerebral palsy: a pilot study of a group circuit training class for children aged 4-8 years. Clin Rehabil 2003;17:48-57.

16. Hesse S, Bertelt C, Schaffrin A, Malezic M, Mauritz KH. Restoration of gait in nonambulatory hemiparetic patients by treadmill training with partial body-weight support. Arch Phys Med Rehabil 1994;75:1087-93.

17. Schindl MR, Forstner C, Kern H, Hesse S. Treadmill training with partial body weight support in nonambulatory patients with cerebral palsy. Arch Phys Med Rehabil 2000;81:301-6.

18. Salavati M, Krijnen WP, Rameckers EA, Looijestijn PL, Maathuis CG, van der Schans CP, et al. Reliability of the modi- 
fied Gross Motor Function Measure-88 (GMFM-88) for children with both Spastic Cerebral Palsy and Cerebral Visual Impairment: A preliminary study. Res Dev Disabil 2015;45-46:32-48.

19. Ross SA, Engsberg JR. Relationships between spasticity, strength, gait, and the GMFM-66 in persons with spastic diplegia cerebral palsy. Arch Phys Med Rehabil 2007;88:1114-20.

20. Park J, Yoo C. Effects of task-oriented training on upper extremity function and performance of daily activities by chronic stroke patients. J Phys Ther Sci 2015;27:2657-9.

21. Timmermans AA, Spooren AI, Kingma H, Seelen HA. Influence of task-oriented training content on skilled arm-hand performance in stroke: a systematic review. Neurorehabil Neural Repair 2010;24:858-70.

22. Radtka S, Hone R, Brown C, Mastick J, Melnick ME, Dowling
GA. Feasibility of computer-based videogame therapy for children with cerebral palsy. Games Health J 2013;2:222-8.

23. Cho C, Hwang W, Hwang S, Chung Y. Treadmill training with virtual reality improves gait, balance, and muscle strength in children with cerebral palsy. Tohoku J Exp Med 2016;238:213-8.

24. Katz-Leurer M, Rotem H, Keren O, Meyer S. The effects of a 'home-based' task-oriented exercise programme on motor and balance performance in children with spastic cerebral palsy and severe traumatic brain injury. Clin Rehabil 2009;23:714-24.

25. Drouin LM, Malouin F, Richards CL, Marcoux S. Correlation between the gross motor function measure scores and gait spatiotemporal measures in children with neurological impairments. Dev Med Child Neurol 1996;38:1007-19. 